\title{
A time-dependent Green's function-based model for stream-unconfined aquifer flows
}

\author{
Taigbenu AE \\ Department of Civil \& Water Engineering, National University of Science \& Technology, PO Box AC939, Bulawayo. Zimbabwe
}

\begin{abstract}
A numerical formulation that is based on the Green element method (GEM), which incorporates a time-dependent Green's function, is used to solve transient two-dimensional flows of stream-unconfined aquifer interaction. The Green's function comes from the fundamental solution to the linear diffusion differential operator in two spatial dimensions. In classical boundary element applications, this Green's function has found use primarily in linear heat transfer and flow problems; its use here for the nonlinear stream-unconfined aquifer flow problem represents the computational flexibility that is achieved with a Green element sense of implementing the singular integral theory. The nonlinear discretised element equations obtained from numerical calculations are linearised by the Picard and Newton-Raphson methods, while the global coefficient matrix, which is banded and sparse, is readily amenable to matrix solution routines. Using four numerical examples, the accuracy of the current formulation is assessed as against an earlier one that incorporates the Logarithmic fundamental solution. It is observed that comparable accuracy is achieved between both formulations, indicating that the current formulation is a viable numerical solution strategy for the stream-aquifer flow problem.
\end{abstract}

Keywords: stream-aquifer interaction; Green element method; linearisation algorithms; numerical solutions

\section{Introduction}

Stream-aquifer interaction flows have gained considerable interest among hydrologists for quite a while because of their applications in hydrograph analysis. Of interest is estimating the baseflow from the recession hydrograph of a stream or river that could be the only water source on which surrounding communities depend for agricultural and domestic uses (Butterworth et al. 1999). This is particularly important in arid and semi-arid environments where rainfall is low and erratic, and droughts are common. Modelling of flow when there is interaction between an unconfined aquifer and a stream has generally followed two approaches. The first is based on the mathematical description of the flow with the nonlinear free-surface (water table) boundary condition being explicitly applied (Dillon and Liggett, 1983; Cabrera and Marino, 1976a; Ibrahim and Brutsaert, 1965). In this approach a vertical slice of the aquifer is considered, and the seepage face that exist at the aquiferstream interface is captured. The drawback to this approach is that the regional distribution of flow in the aquifer and the variability of baseflow along the reach of the stream are not accounted for. This approach is suitable in instances when it can be justified that flow variability along the streamwise direction is negligibly small. The second approach is based on depth-averaging of the governing flow differential equation so that the free-surface condition is implicitly imbedded in the resulting differential equation, and the seepage face is assumed to be non-existent (Hornberger et al., 1970). By this approach, the flow is now essentially horizontal, the vertical velocity component of flow is assumed to be negligible, and the hydraulic head is assumed to be depth-invariant. These assumptions are widely known in the groundwater literature as the Dupuit-

푱263-9-282007; fax: 263-9-286803; e-mail: taigbenu@hotmail.com Received 12 December 2002; accepted in revised form 14 April 2003.
Forchheimmer assumptions and the approach is the hydraulic one. Because the ratio of the depth to lateral dimensions of most aquifers is extremely small, this assumption is valid for most parts of the aquifer but breaks down within the vicinity where flow occurs in and out of the aquifer. One advantage of this approach is that the regional distribution of base flow can be accounted for. The alternative to either of these approaches would be to adopt the hydrodynamic viewpoint whereby the governing differential equation is solved in three dimensions with the non-linear free-surface explicitly imposed. Apart from the huge computational requirements of this approach, data on hydrogeological parameters of most aquifers are not gathered to such details as to make them available for use in this model. In the best of circumstances, hydrogeological parameters from field investigations are obtained in a depth-averaged manner. It is for these reasons that the hydraulic approach is followed in this paper.

Solution strategies to stream-unconfined aquifer flows have also taken a number of directions. Experimental investigations that are designed on the Hele-Shaw apparatus have commonly been used (Ibrahim and Brutsaert, 1965; Rochester and Kriz, 1968). Though quite limited in terms of versatility of application, experimental models have provided useful insight into the phenomenon of stream-aquifer interaction flows and have served to validate other solution strategies.

The other solution strategies are analytical and numerical. To date, there is no analytic solution to the vertical slice approach where the non-linear free-surface condition is explicitly prescribed. The only widely reported exact solution to the hydraulic approximation of flow is that proposed by Boussinesq (1904) who used similarity considerations to derive the solution of flow from an aquifer into a ditch. The other analytical solutions reported in the literature were achieved after some form of simplification or linearisation was applied to the non-linear differential equation (Desai, 1973; Lockington, 1997). All these solutions apply to one spatial flow direction, with rather idealised boundary and/or initial 


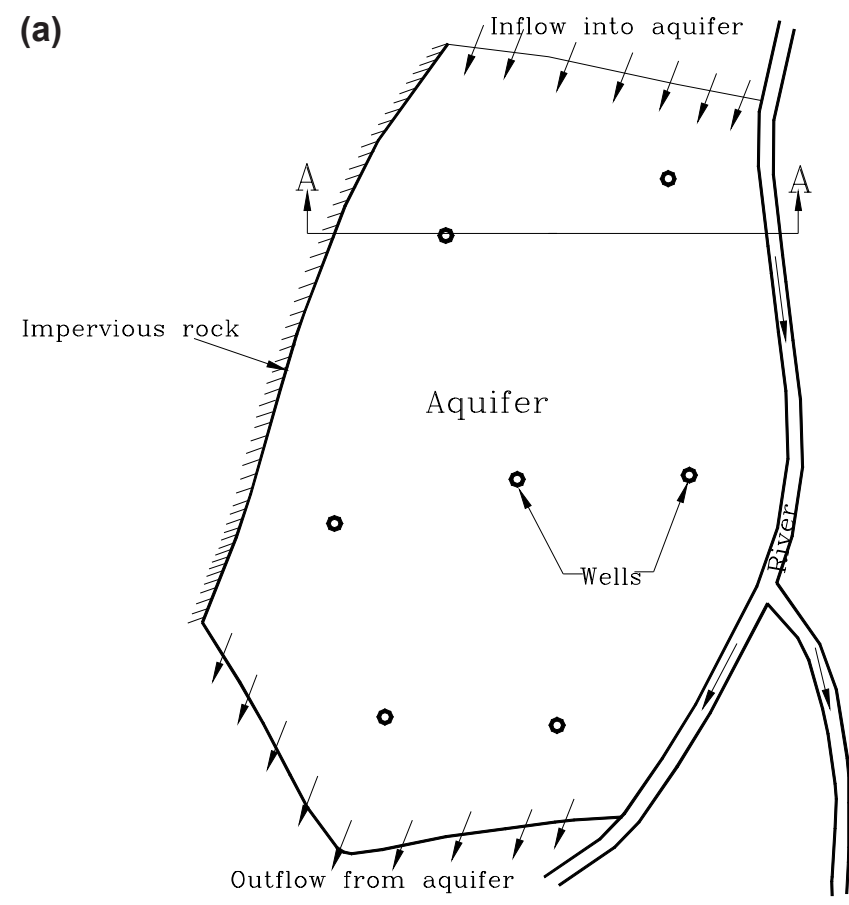

(b)

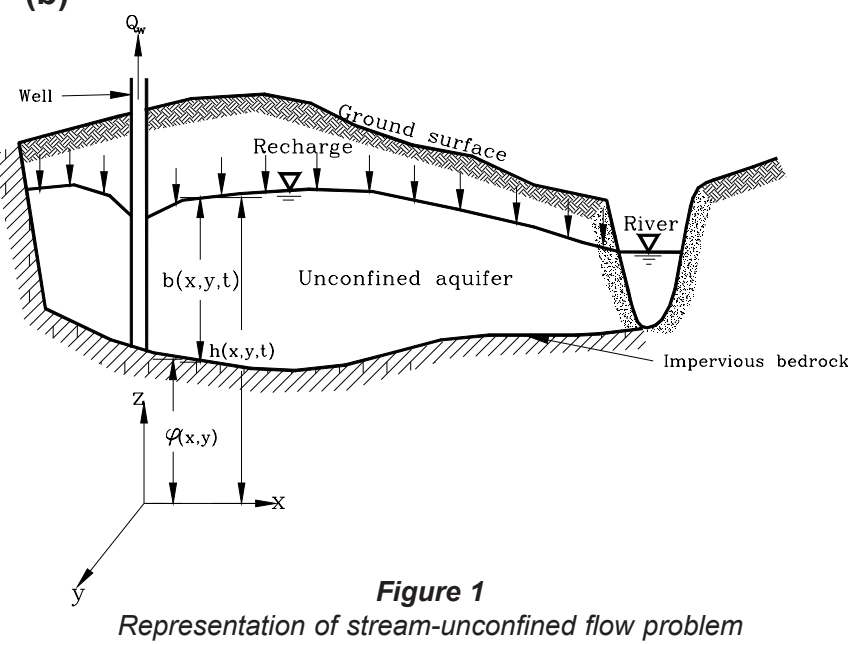

(a) plan, (b) section

conditions being applied. It is these restrictions that limit the use of analytical techniques, except to validate numerical techniques.

Numerical techniques have been widely applied to streamunconfined flow problems. Among them are finite difference, finite element, boundary element, and Green element methods. Using the vertical slice with the free-surface boundary conditions explicitly applied, Cabrera and Marino (1976) applied the finite element method (FEM), while Dillon and Liggett (1983) applied the boundary element method (BEM). Adopting the hydraulic approach, FDM was utilised by Hornberger et al. (1970), while Taigbenu and Liggett (1986) applied BEM, Onyejekwe et al. (1999) used GEM in one spatial dimension, and Taigbenu and Onyejekwe (1999) in two spatial dimensions. The Green element formulation proposed herein offers a viable alternative approach to solving the stream-unconfined flow problem. It utilises a timedependent Green's function of the diffusion differential operator which traditionally has been used for linear heat conduction problems. Here, it is applied to the non-linear unconfined flow problem in a novel way that accommodates medium heterogeneity, varying bedrock profile, and point and distributed sources and sinks with varying strengths in space and time. The theoretical basis of GEM is founded on a singular integral theory while its implementation is based on an element-by-element approach (Taigbenu, 1995; 1999). The current formulation is tested on four numerical examples to demonstrate its capabilities, while its accuracy is validated with results from other techniques. It is found to exhibit a unique numerical feature that at first glance is unconventional. For a given spatial discretisation, the formulation does give more accurate solutions with larger time step. We provide, in this paper, a heuristic explanation for this feature. The fourth example is one which demonstrates the ability of this formulation to evaluate discharge in and out of an aquifer under practically realistic conditions.

\section{Mathematical statement and Green element formulation}

Figs. $1 \mathrm{a}$ and $1 \mathrm{~b}$ provide sketches of the plan and section of the problem being addressed. Hydrogeological parameters of the aquifer are allowed to have spatial variation (heterogeneity), and bedrock elevation varies in space. Applying the mass balance equation at the differential scale coupled with the Darcy law, and integrating the result over the flow thickness of the aquifer, give the equation that describes flow of an incompressible fluid in an unconfined aquifer (Bear, 1979) :

$$
\begin{aligned}
& \nabla \cdot[K(h-\phi) \nabla h] \\
& \text { where: }
\end{aligned}
$$

$h \equiv h(x, y, t)$ is the hydraulic head or water table elevation above a datum,

$\nabla=i \partial / \partial x+j \partial \partial y$ is the two-dimensional gradient operator,

$K=K(x, y)$ is the hydraulic conductivity,

$\phi=\phi(\mathrm{x}, \mathrm{y})$ is the bedrock elevation,

$n$ is the specific yield or effective porosity of the aquifer,

$f$ accounts for distributed recharge from natural and artificial sources, while

$p$ takes into account pumping stresses.

The contribution from these point sources/sinks is expressed mathematically as:

$$
p=\sum_{w=1}^{N_{w}} Q_{w}(t) \delta\left(x-x_{w}\right) \delta\left(y-y_{w}\right)
$$

$Q_{w}(t)$ is the strength or discharge rate of a well located at

$\left(x_{w}, y_{w}\right)$,

$\delta$ is the Dirac delta function, and

$\mathrm{N}_{\mathrm{w}}$ is the number of such wells.

Denoting the flow depth as $b(x, y, t)=h(x, y, t)-\phi(x, y)$, and defining a psuedo-transmissivity $T$ as $T=T(x, y, t)=K b$, Eq. (1) becomes:

$$
\nabla \cdot(T \nabla h)=n \frac{\partial h}{\partial t}+f(x, y, t)+p(x, y, t)
$$

To solve Eq. (3), known conditions for the water table elevation or the flux across the boundary have to be specified, in addition to the distribution of the water table everywhere in the aquifer at the initial time. We admit the $1^{\text {st }}$-type boundary condition of known water level of the stream along the reach where it is in contact with the aquifer. In that case, the condition is expressed as:

$$
h(x, y, t)=H(x, y, t) \text { on } \Gamma_{1}
$$


When the flux in or out of the aquifer is known, the $2^{\text {nd }}$ type condition is given by:

$$
-T \nabla h \cdot \boldsymbol{n}=q(x, y, t) \text { on } \Gamma_{2}
$$

in which

$q$ is the normal flux,

$\Gamma=\Gamma^{1}+\Gamma^{2}$ is the boundary of the aquifer, and

$\boldsymbol{n}$ is the outward pointing unit normal vector on the boundary.

The time dependency of the problem requires that the distribution of the water table be specified throughout the aquifer at the initial time $t_{0}$.

There is now a fair amount of appreciation of the Green element formulation to allow for a succinct presentation. It proceeds along the steps that have been outlined in such references as Taigbenu $(1995 ; 1999)$. These steps are summarised below:

(i) Obtain the singular fundamental solution to an appropriate auxiliary equation to the flow Eq (3);

(ii) Transform the flow equation into an integral one using Green's second identity;

(iii) Discretise the flow region into suitable polygonal elements over which the distribution of the dependent variables is prescribed;

(iv) Derive the discretised form of the integral representation for each element (element equation);

(v) Effect the boundary and initial conditions in the system of element equations;

(vi) Aggregate the element equations for all the elements, imposing the compatibility relations across element boundaries;

(vii) Linearise the resultant non-linear global element equations by a suitable linearisation algorithm.

The resultant global coefficient matrix from this formulation is sparse and banded and, therefore, amenable to efficient commercially available matrix solvers.

In this work, rectangular elements have been employed for regular computational domains, and triangular elements, because of their boundary-matching characteristics, for irregular ones. Within each element, denoted as $\Omega^{(\mathrm{e})}$, the medium is considered homogeneous so that, in essence, the entire domain is piece-wise homogeneous. In other words, flow depth and medium parameters are allowed to vary from element to element in a piece-wise homogeneous fashion. With this, Eq. (3) takes the following form for each element

$$
\bar{D} \nabla^{2} h-\frac{\partial h}{\partial t}=\bar{F}(x, y, t)+\bar{P}
$$

in which

$$
\mathrm{D}=\mathrm{T} / \mathrm{n}
$$

$\mathrm{F}=\mathrm{f} / \mathrm{n}$ and

$\mathrm{P}=\mathrm{p} / \mathrm{n}$, where the bar on each of the quantities indicates that those quantities are evaluated at the centroid of the element.

The fundamental solution of the auxiliary equation

$$
\begin{aligned}
& \nabla^{2} G=\frac{1}{\overline{\mathrm{D}}} \frac{\partial \mathrm{G}}{\partial \mathrm{t}}=\delta\left(\mathrm{r}-\mathrm{r}_{\mathrm{i}} ; \mathrm{t}-\tau\right), \text { given by } \\
& G\left(r, t ; r_{i}, \tau\right)=\frac{H(t-\tau)}{\bar{D}(t-\tau)} \exp \left[-\frac{\left(r-r_{i}\right)^{2}}{4 \bar{D}(t-\tau)}\right]
\end{aligned}
$$

is used in conjunction with Green's second identity to transform the differential equation into an integral one (Taigbenu, 2003): $\lambda h_{i}^{(2)}+\bar{D} \int_{t_{1} \Gamma^{(e)}}^{t_{2}} \int\left[h(r, \tau) \nabla G\left(r, t_{2} ; r_{i}, \tau\right) \cdot \boldsymbol{n}-G\left(r, t_{2} ; r_{i}, \tau\right) \nabla h \cdot \boldsymbol{n}\right] d \tau d s$

in which: $\Omega^{(e)}$

$$
-\iint_{\Omega^{(e)}} G\left(r, \Delta t ; r_{i}, 0\right) h^{(1)}(r) d A+\int_{t_{1}}^{t_{2}} \int_{\Omega^{(e)}} G\left(r, t_{2}, r_{i}, \tau\right)[\bar{F}+\bar{P}] d A d \tau=0
$$

$\lambda$ equals twice the nodal angle at the source node, and the superscripts 1 and 2, respectively, denote the previous time level $\mathrm{t}_{1}$ and the current time level $\mathrm{t}_{2}$.

Though Eq. (7) applies to a typical element, it is nonetheless similar to the integral equation in boundary element formulations.

\section{Numerical implementation}

The implementation of Eq. (7) is fairly straightforward; the distribution of functional quantities is specified over the spatial element and in time by interpolation functions. Linear interpolation functions in space and time are employed. Those functions approximate any of the functional quantities, for instance $h$, by the expression:

$$
h=N_{j}(r) N^{(m)}(\tau) h_{j}^{(m)} ; \quad j=1,2, \ldots g, m=1,2
$$

where:

$g$ represents the number of nodes in the element,

$m$ is indicative of the time, with $m=1$ denoting the previous time and $m=2$ denoting the current time, and

$\mathrm{N}_{\mathrm{j}}(\mathrm{r})$ and $\mathrm{N}^{(\mathrm{m})}(\tau)$ are linear interpolation functions in space and time, respectively.

It should be noted that the summation convention for a repeated index applies similarly to the superscripted index. Simplifying the normal derivative of the Green's function by: where:

$$
\nabla G\left(r, t_{2} ; r_{i}, \tau\right) \cdot \boldsymbol{n}=\frac{-\eta}{2 \bar{D}\left(t_{2}-\tau\right)} G\left(r, t_{2} ; r_{i}, \tau\right)
$$

$\eta$ is the normal distance from the source node $\mathrm{r}_{\mathrm{i}}=\left(x_{\mathrm{i}}, y_{\mathrm{i}}\right)$ to the boundary (see Fig. 2), and introducing Eqs. (8) and (9) into Eq. (7) yields:

$$
\begin{aligned}
& \lambda h_{i}^{(2)}-\bar{D} \int_{0}^{\Delta t} \int_{\zeta_{1}}^{\zeta_{2}}\left[\frac{\eta}{2 \bar{D}(\Delta t-\tau)} h_{j}^{(m)}+\frac{\partial h_{j}^{(m)}}{\partial n}\right] N_{j}(\zeta) N^{(m)}(\tau) G\left(\zeta, \Delta t ; \zeta_{i} \tau\right) d \tau d \zeta(10) \\
& -\iint_{\Omega^{(e)}} G\left(r, \Delta t, r_{i}, 0\right) N_{j}(r) h_{j}^{(1)} d A+\iint_{0}^{\Delta t} \int_{\Omega^{(o)}} G\left(r, \Delta t ; r_{i} \tau\right)[\bar{F}+\bar{P}] d A d \tau=0
\end{aligned}
$$

When Eq. (10) is expressed slightly differently in terms of the normal boundary flux $q=-T \partial h / \partial n$ rather than in terms of $\partial h / \partial n$, it offers a more accurate and stable numerical scheme. The reasons for this are not far-fetched: continuity of the flux across elements is assured by this approach, thereby enhancing accuracy and stability of the formulation, and a higher level of accuracy of the fluxes on the external boundaries, that are directly computed, is achieved (Taigbenu, 2001a; 2001b). With the normal boundary flux introduced into Eq. (10), the element equation in matrix form becomes:

$$
B_{i j}^{(m)} h_{j}^{(m)}-S_{i j} h_{j}^{(1)}+L_{i j}^{(2)} q_{j}^{(2)}+L_{i j}^{(1)} \frac{\bar{T}^{(2)}}{\bar{T}^{(1)}} q_{j}^{(1)}+V_{i j} F_{j}+U_{i}=0
$$

in which:

$$
B_{i j}^{(m)}=\lambda \delta_{i j} \delta^{(m 2)}-\frac{\eta}{2} \int_{0}^{\Delta t} \int_{\zeta_{1}}^{\zeta_{2}} \frac{1}{(\Delta t-\tau)} N_{j}(\zeta) N^{(m)}(\tau) G\left(\zeta, \Delta t ; \zeta_{i}, \tau\right) d \tau d \zeta
$$

$$
L_{i j}^{(m)}=\frac{1}{\bar{n}} \int_{0}^{\Delta t} \int_{\zeta_{1}}^{\zeta_{2}} N_{j}(\zeta) N^{(m)}(\tau) G\left(\zeta, \Delta t ; \zeta_{i}, \tau\right) d \tau d \zeta
$$




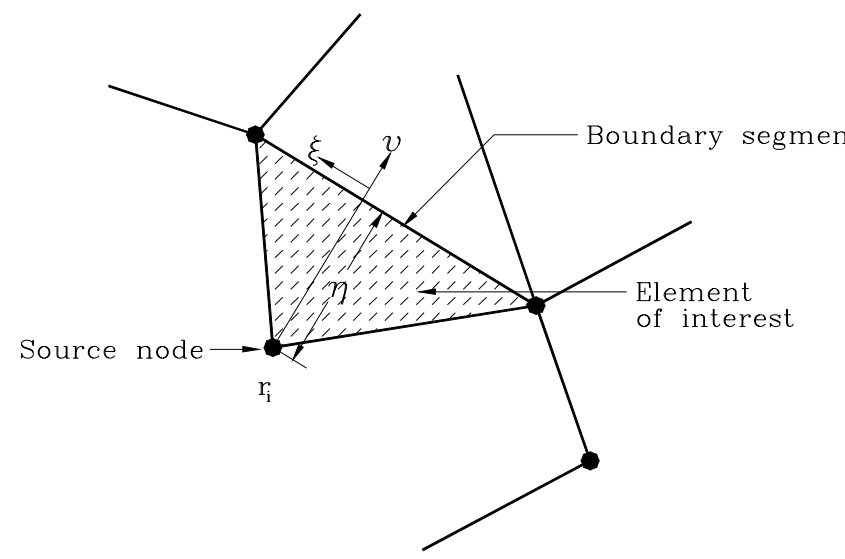

Figure 2

Typical element over which integration is performed

$$
\begin{aligned}
S_{i j} & =\iint_{\Omega^{(e)}} G\left(r, \Delta t ; r_{i}, 0\right) N_{j}(r) d A \\
V_{i j}^{(m)} & =\int_{0}^{\Delta t} \iint_{\Omega^{e}} G\left(r, \Delta t ; r_{i}, \tau\right) N_{j}(r) N^{(m)}(\tau) d A d \tau \\
U_{i} & =\frac{Q_{w}}{\bar{T}} E\left[\frac{\left(r_{i}-r_{w}\right)^{2}}{4 \bar{D} \Delta t}\right]
\end{aligned}
$$

where:

$E$ is the exponential integral.

Unlike in classical boundary element methodology where domain integrations present some computational challenges, the feature of the source and field nodes being always located in the same element provides significant simplification of domain integrations in Green element calculations (Fig. 2). The domain integrals are either implemented analytically so that their outcomes reflect the geometrical properties of the element or are done numerically by standard Gauss quadrature techniques. One must not fail to point out the ease with which the contribution of sources and sinks is handled in Green element calculations. That contribution, $U_{\mathrm{i}}$, is effected nodally only within an element in which the source/sink node is located. It is this feature that makes the method most attractive for well hydraulics problems. The computer code that has been developed on the basis of Eq. (11), incorporating the timedependent fundamental solution of Eq. (6), is referred to as model 2. An earlier code that uses the Logarithm fundamental solution is referred to as model 1 (Taigbenu and Onyejekwe, 1999). Comparison of both models is carried out in a subsequent section of this paper.

The outcomes of the boundary and domain integrals are essentially the Exponential Integral, E $(\psi)$, Exponential, $\mathrm{e}^{-\psi}$, and Error function, $\operatorname{erf}(\psi)$, where the argument has the expression

$$
\psi=\frac{l^{2}}{4 \bar{D} \Delta t}
$$

In Eq. (13), $l$ is indicative of the element size. Of these three functions, it is only the Exponential Integral that exhibits a logarithmic singularity for small values of its argument. In addition, it decays more rapidly to zero than the Exponential function for moderate values of $\psi$. Since GEM is essentially a singular integralbased numerical formulation, it means that the Exponential Inte- gral plays the most dominant role in determining the essential nature of the numerical solution. It is for this reason that the argument of the Exponential Integral should not be too large to preclude its contribution, thereby compromising the quality of the numerical solution. To have small values of $\psi$, it is either that the element size is small or the time step is large or both. Though $\psi$ varies as the square of the element size, which means that a reduction in element size has significant influence on the value of $\psi$, it is nonetheless computationally imprudent to significantly reduce the element size because of the additional computing resources required to handle increased number of elements. It is rather advantageous to increase the time step, thereby reducing the value of $\psi$ so that fewer simulation intervals are implemented. The expected improvement in the quality of the numerical solution from adopting a larger time step is consistent with our earlier results when the one spatial dimension version of this same Green's function was applied to some one-dimensional problems (Taigbenu, 1999; Taigbenu and Onyejekwe, 1999). It is quite reasonable to expect that the time step can not be increased ad infinitum. The upper limit to the increase of the time step depends on how well the interpolation function approximates the variation of the primary variable in time. This point is revisited in the discussion of the simulations of one of the numerical examples.

The global contribution of Eq. (11) for all the elements is achieved by aggregating the element equations in such a way that the nodal unknowns on the external boundaries are either $h$ or $q$ (whichever is not specified by the boundary conditions), and $h$ at the internal nodes. This is done in such a way that the compatibility requirements for the flux and hydraulic heads at inter-element boundaries are met. The global matrix equation is

$$
A_{i j}(\bar{D}) u_{j}^{(2)}=R_{i}
$$

where:

$A_{i j}$ is a banded coefficient matrix whose elements depend on the hydraulic heads,

$u_{j}^{(2)}=\left\{h_{j}^{(2)}, q_{j}^{(2)}\right\}^{T}$ is a mixed vector of unknowns, and

$R_{i}$ is a known vector that accounts for the boundary, initial data, and contribution from point and distributed recharge.

\section{Linearisation of matrix equation}

The global matrix equation is non-linear since the elements of the coefficient matrix depend on $\overline{\mathrm{D}}$ which, in turn, is dependent on the water table elevation. Two commonly used algorithms for linearising such discrete non-linear equations are the Picard and NewtonRaphson (N-R) algorithms.

The Picard algorithm linearises Eq. (14) at any iteration level $k$ by providing estimates of the solution, $u_{j}^{(2, k)}$, with which $\overline{\mathrm{D}}$ is evaluated. The refined estimate of the solution $u_{j}^{(2, k+1)}$ can then be obtained by solving the global matrix Eq. (14). The iteration process continues till the mean of $\left|u_{j}^{(2, k+1)}-u_{j}^{(2, k)}\right|$ at all nodal points falls below a prescribed tolerance value $\varepsilon$.

The N-R algorithm calculates refined estimates of the solution by adding an increment, $\Delta u_{j}^{(2, k+1)}$, to the known solution estimate, that is:

$$
u_{j}^{(2, k+1)}=u_{j}^{(2, k)}+\Delta u_{j}^{(2, k+1)}
$$

The increment is obtained from the Jacobian matrix

$$
J_{i j}^{(k)} \Delta u_{j}^{(2, k+1)}=-g_{i}^{(k)}
$$

where the Jacobian $\mathrm{J}_{\mathrm{ij}}{ }^{(\mathrm{k})}$ is evaluated by a chord slope of the coefficient matrix. That is: 
$J_{i j}^{(k)}=\left.\frac{\partial g_{i}}{\partial u_{j}}\right|_{u_{j}=u_{j}^{(2, k)}}=A_{i j}^{(k)}+\frac{\partial A_{i m}^{(k)}}{\partial u_{j}} u_{m} \approx A_{i j}^{k}+\frac{\left(A_{i m}^{(k)}-A_{i m}^{(k-1)}\right) u_{m}^{(2, k)}}{u_{j}^{(2, k)}-u_{j}^{(2, k-1)}}$

where:

$$
g_{i}=A_{i j}(\bar{D}) u_{j}-R_{i}
$$

Convergence is achieved when the mean $\left|\Delta \mathrm{u}_{i}^{(2, k+1)}\right|$ at all the nodal points falls below $\varepsilon$. Both linearisation algorithms can be incorporated in the Green element formulation. However, only the Picard algorithm has been used in the computer code used in solving the examples in the next section.

\section{Numerical examples}

Four numerical examples of transient stream-unconfined flows are used to demonstrate the capabilities of the current Green element model (model 2). They include cases of the Boussinesq example which has an exact solution, an aquifer response to a rising and falling river flood stage, transient example of the Dupuit problem, and a regional groundwater flow example where the aquifer receives varying point and distributed pumping stresses and interacts with an adjoining river.

\section{Example 1}

This is one of the very rare examples of non-linear unconfined flow with an exact solution. It is one-dimensional flow from an unconfined aquifer into a stream with a dry bed. The other end of the aquifer is a no-flux boundary, and initially there is a water table distribution $\mathrm{H}_{0}(\mathrm{x})$ that is implicitly defined by the integral expression:

$$
x=\frac{1}{B(2 / 3,1 / 2)} \int_{0}^{H_{0}^{3}(x)}(1-\zeta)^{-1 / 2} \zeta^{-1 / 3} d \zeta=\frac{B_{H_{0}^{3}(x)}(2 / 3,1 / 2)}{B(2 / 3,1 / 2)}
$$

where:

$\mathrm{B}(2 / 3,1 / 2)$ and $\mathrm{B}_{\mathrm{H}^{3}(\mathrm{x})}\left(2 /{ }_{3}, 1 / 2\right)$ are the complete and incomplete Beta functions, respectively. The exact solution to the problem is given by Boussinesq (1904) using similarity considerations:

$$
h(x, t)=\frac{H_{0}(x)}{[1.1155 t+1]}
$$

and the discharge into the stream is

$$
q=\frac{0.8624}{[1.1155 t+1]^{2}}
$$

The current model is applied, discretising the region into 10 uniform rectangular elements of $0.1 \times 0.1$ and a uniform time step of 0.05 . The numerical and exact solutions for the water table distribution and discharge to the stream are presented in Figs. 3a and $3 \mathrm{~b}$. It is observed that the numerical solution correctly reproduces the exact solution for both the hydraulic head and outflow discharge from the aquifer.

\section{Example 2}

This example represents the transient scenario of the Dupuit problem in which interaction occurs between an unconfined aquifer that is sandwiched by two rivers or reservoirs maintained at $33 \mathrm{~m}$ and $21 \mathrm{~m}$ elevations above the bedrock of the aquifer. The flow is considered to be along the $300 \mathrm{~m}$ length of the aquifer between the rivers, and a uniform recharge of $8 \mathrm{~mm} / \mathrm{h}$ from precipitation is received by the aquifer. Initially the water table distribution is linear, that is, $\mathrm{h}=33-0.04 \mathrm{x}$. With hydraulic conductivity value of $0.6 \mathrm{~m} / \mathrm{h}$ and specific yield of 0.2 , the current
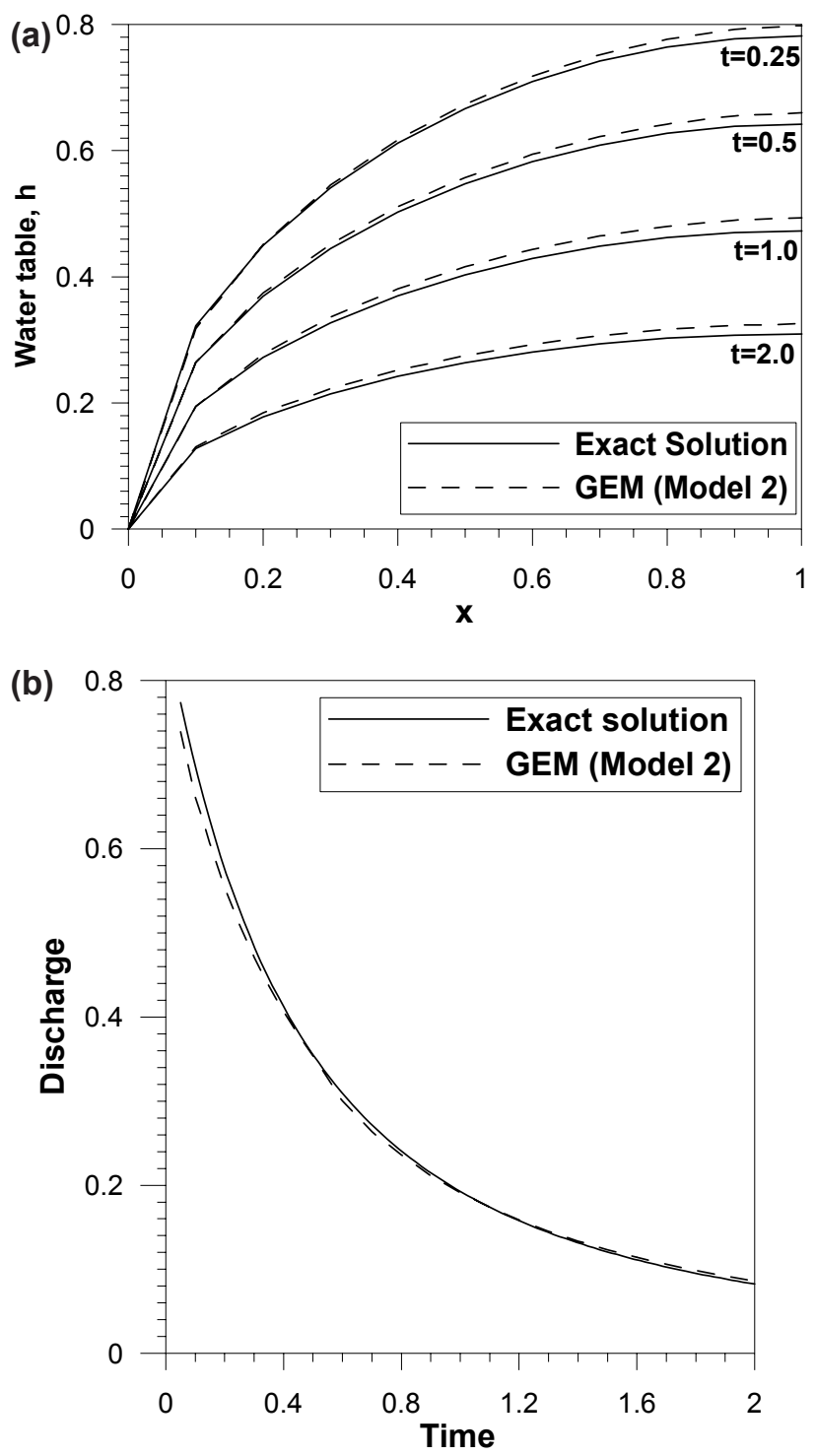

Figure 3

Green element and exact solutions of example 1

(a) Water table at various times, (b) Discharge into stream

Green element model is applied by discretising the flow region into 10 square elements of $30 \mathrm{~m}$ length, and adopting a time step of $30 \mathrm{~h}$ for the first $600 \mathrm{~h}$ and $60 \mathrm{~h}$ thereafter till $1200 \mathrm{~h}$. At each time step, a tolerance value $\varepsilon$ of $10^{-5}$ is achieved at the end of six iterations. This is an indication that the current formulation has excellent convergence characteristics. The steady-state solution, widely referred to as the Dupuit solution in the groundwater literature, is given as

$$
h(x, t)=\frac{N x(L-x)}{K}+\left(H_{L}-H_{0}\right) \frac{x}{L}+H_{0}
$$

where in our case, $\mathrm{H}_{0}=33 \mathrm{~m}, \mathrm{H}_{\mathrm{L}}=21 \mathrm{~m}, \mathrm{~N}=0.008 \mathrm{~m} / \mathrm{h}, \mathrm{L}=300$ $\mathrm{m}$, and $\mathrm{K}=0.6 \mathrm{~m} / \mathrm{h}$. We observe that the solution from the current model at $1200 \mathrm{~h}$ approaches the steady state solution given by Eq. (20) (Fig. 4a). Similarly the predicted discharge from the aquifer into the two rivers for large times closely approximates the steady state discharge values of $0.552 \mathrm{~m} / \mathrm{h} \cdot \mathrm{m}$ to the river at $33 \mathrm{~m}$ water level and $1.848 \mathrm{~m} / \mathrm{h} \cdot \mathrm{m}$ to the river at $21 \mathrm{~m}$ water level (Fig. $4 \mathrm{~b}$ ). The significance of correctly predicting the discharge hydrograph 

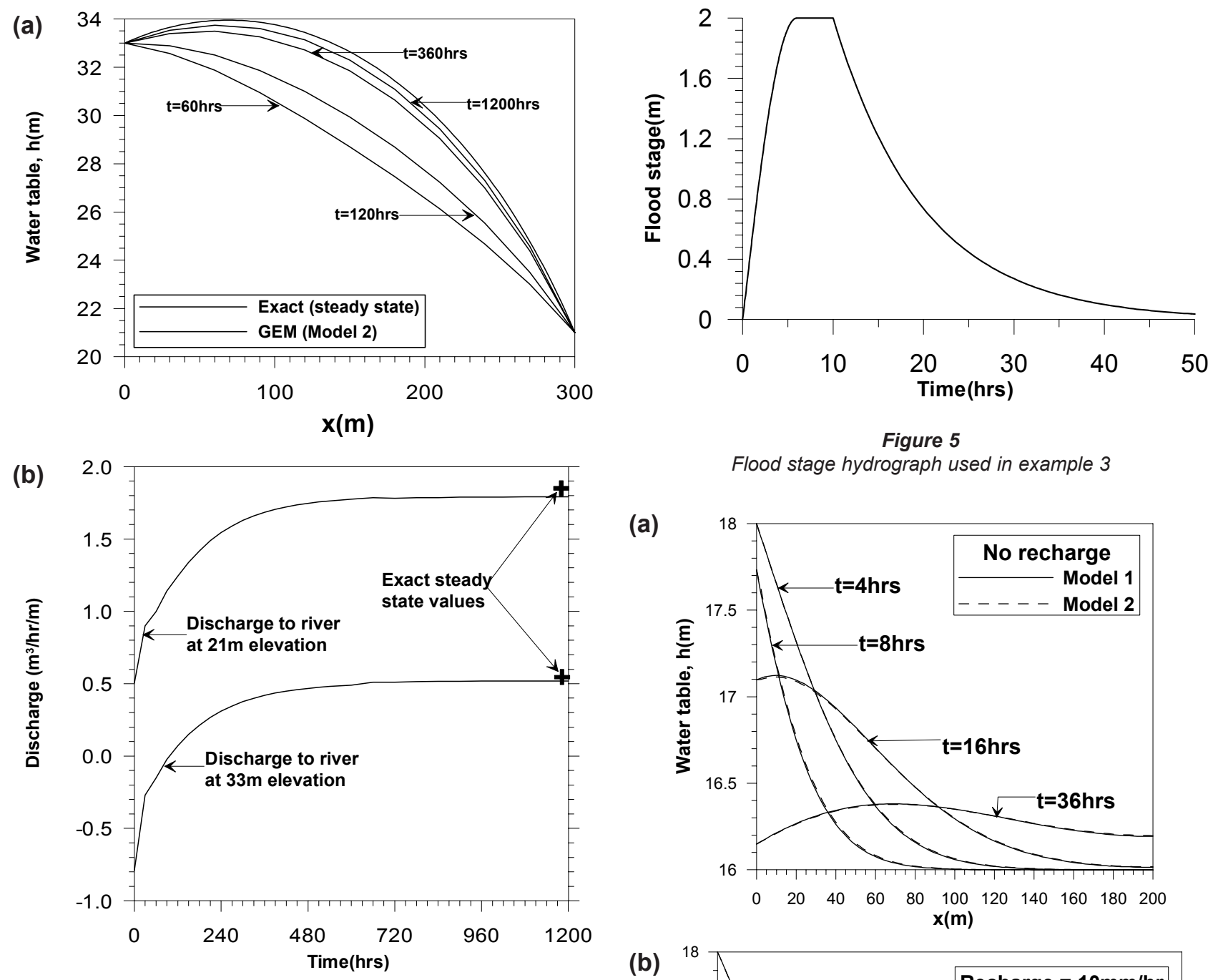

Figure 5

Flood stage hydrograph used in example 3

(a)

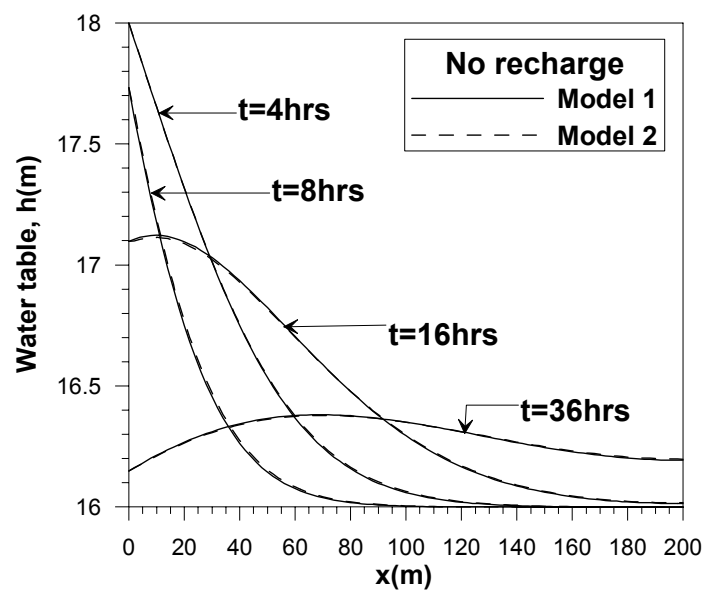

Figure 4

Simulation results of example 2 showing transient Green element solutions and steady Dupuit solution (a) Water table distribution,

(b) Discharge into rivers

at the outlet of the aquifer is realised in surface flow modelling which takes the predicted discharge hydrograph as one of its input data.

\section{Example 3}

This third example represents one of the aquifer's response to a flood wave on an adjoining river. The water table and river stage were at the same elevation of $16 \mathrm{~m}$ above the bedrock before the flood wave on the river. The flood stage variation with time is shown in Fig. 5, and it is approximated by a sinusoidal variation for the first $6 \mathrm{~h}$, and maintains a crest value of $2 \mathrm{~m}$ for the next $4 \mathrm{~h}$ after which it decays exponentially with a depletion rate of $0.1 \mathrm{~h}^{-1}$. The flow in the aquifer, which is considered to be essentially along its length of $200 \mathrm{~m}$, takes place under conditions of the river stage at one end of the aquifer and zero flux at its other end. The hydraulic conductivity and specific yield of the aquifer are respectively $3.6 \mathrm{~m} /$ $h$ and 0.35 . Two cases of infiltration fluxes from natural recharge are considered: the first without recharge and the second with a uniform recharge of $10 \mathrm{~mm} / \mathrm{h}$. The flow region is discretised into 50 square elements each $2 \mathrm{~m}$ in length, and a uniform time step of $0.5 \mathrm{~h}$ is incorporated in the current model (model 2). The same spatial discretisation is employed in model 1 with a time step of

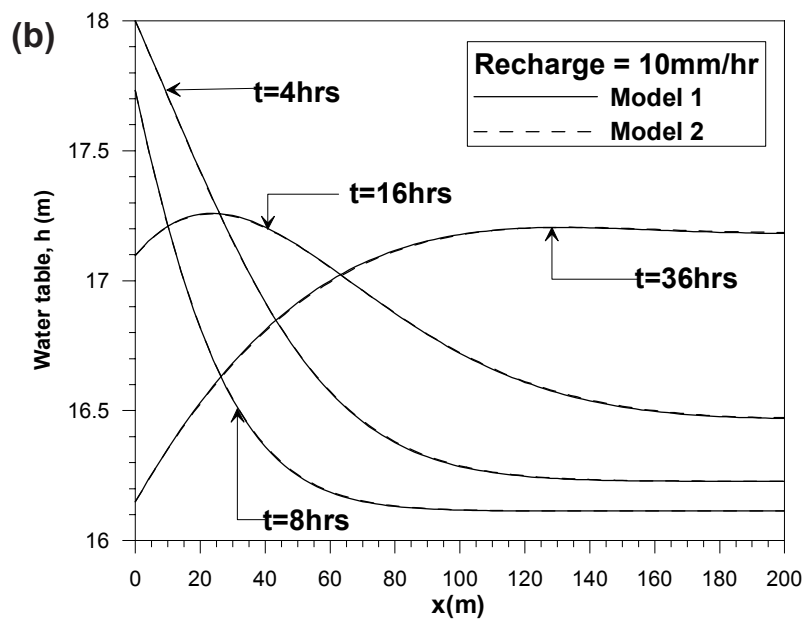

Figure 6

Green element prediction of water table distribution for example 3 (a) No recharge, (b) with recharge of $10 \mathrm{~mm} / \mathrm{h}$

$0.25 \mathrm{~h}$. The numerical results from both models for the water table distribution at different times are presented in Fig. 6a with no recharge and Fig. $6 \mathrm{~b}$ with recharge. The iterative process exhibits a convergence feature in which at each time step a tolerance value $\varepsilon=8 \times 10^{-6}$ is attained at the end of eight iterations. The predicted hydrographs from both models with and without recharge are shown in Fig. 7. There is close agreement between the results from the two Green element models. The example is also used to 


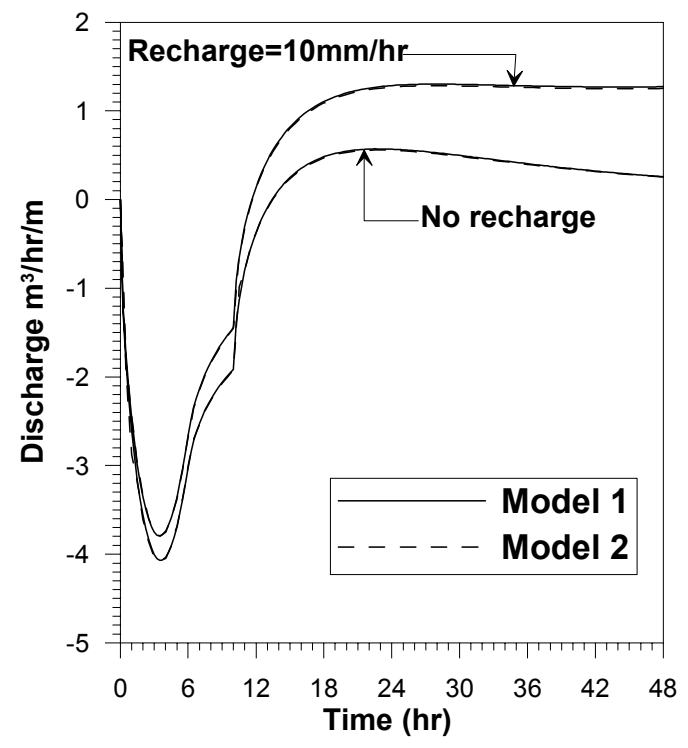

Figure 7

Green element solutions of example 3 for discharge

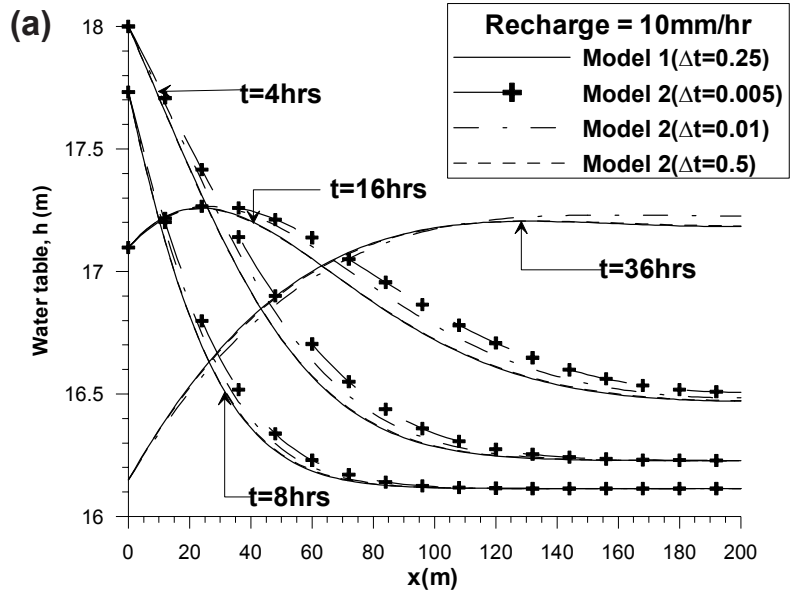

(b)

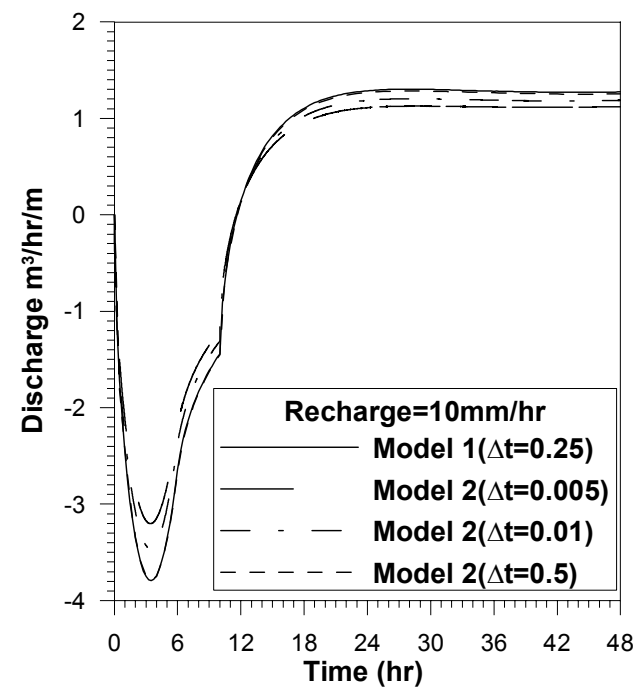

Figure 8

Influence of time step or value of parameter $\psi$ on current Green element solution for example 3

(a) Water table, (b) Discharge.

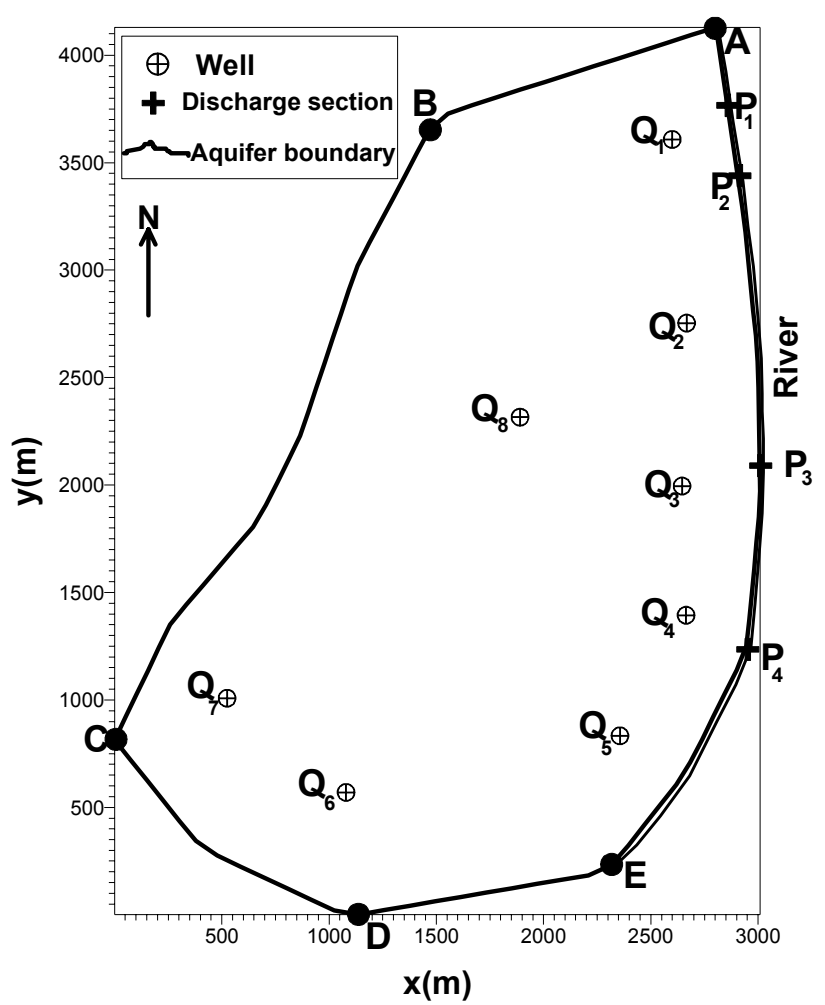

Figure 9

Flow domain of Example 4

demonstrate how the current model is affected by the time step as alluded to previously. In the case of recharge of $10 \mathrm{~mm} / \mathrm{h}$, the water table distribution and hydrograph are obtained with model 2 using time steps of 0.005 .0 .01 and $0.5 \mathrm{hr}$. These time steps correspond to $\psi$ values of approximately $2.4,1.2$, and 0.024 , respectively. We observe in Figs. 8a and 8b how the numerical solution from the present model progressively deteriorates with increasing $\psi$ or decreasing time step. It is a trend that is commonly associated with the formulation based on this time-dependent Green's function. It has also been observed in one-spatial dimension. It is a healthy trend, though, in the sense that accuracy enhancement is achieved with fewer computing resources. In programming the current formulation, we have incorporated a condition on $\psi$ with an upper limiting value of 2.0 .

\section{Example 4}

This fourth example represents a physically realistic streamunconfined flow interaction in which regional flow occurs in an aquifer of $8.1 \mathrm{~km}^{2}$ located west of a river with adjoining length of about $4 \mathrm{~km}$ (see Fig. 9). Eight wells are in operation within the aquifer, and their characteristics in terms of location and abstractions rates are found in Table 1. The aquifer is recharged uniformly by precipitation at a rate of $2.2 \mathrm{~mm} / \mathrm{d}$. The northern and western boundaries of the aquifer, denoted in Fig. 9 as $\mathrm{AB}$ and BC, are noflux boundaries, while the south-western boundary $\mathrm{CD}$ allows in a discharge of $1.7 \mathrm{~m}^{3} / \mathrm{d}$ per metre length of boundary. The southern boundary DE is also a no-flux boundary. Initially the level of water in the aquifer and river is at $40 \mathrm{~m}$ above the aquifer bedrock. Thereafter, the water level in the stream falls exponentially with a depletion rate of $0.04 \mathrm{~d}^{-1}$, that is $h=38+2 e^{-0.04 t}$. The hydraulic conductivity and specific yield of the aquifer are $21.2 \mathrm{~m} / \mathrm{d}$ and 0.2 , respectively. In carrying out the numerical simulations, the aquifer is discretised into 1023 triangular elements with a total of 560 


\begin{tabular}{|c|c|c|}
\hline \multicolumn{3}{|c|}{$\begin{array}{c}\text { TABLE } 1 \\
\text { Data on wells }\end{array}$} \\
\hline $\begin{array}{l}\text { Well } \\
\text { identi- } \\
\text { fication }\end{array}$ & $\begin{array}{l}\text { Well } \\
\text { location }(m) \\
(x, y)\end{array}$ & $\begin{array}{l}\text { Abstraction } \\
\text { rate }\left(\mathrm{m}^{3} / \mathrm{d}\right)\end{array}$ \\
\hline $\mathrm{Q}_{1}$ & 2553,3648 & $1.80 \times 10^{3}$ \\
\hline $\mathrm{Q}_{2}$ & 2631,2719 & $2.10 \times 10^{3}$ \\
\hline $\mathrm{Q}_{3}$ & 2649,2042 & $2.30 \times 10^{3}$ \\
\hline $\mathrm{Q}_{4}$ & 2711,1375 & $2.20 \times 10^{3}$ \\
\hline $\mathrm{Q}_{5}$ & 2357,779 & $1.47 \times 10^{3}$ \\
\hline $\mathrm{Q}_{6}$ & $1075,618.2$ & $2.84 \times 10^{3}$ \\
\hline $\mathrm{Q}_{7}$ & 560,1044 & $2.40 \times 10^{3}$ \\
\hline $\mathrm{Q}_{8}$ & 1930,2304 & $3.60 \times 10^{3}$ \\
\hline
\end{tabular}

(a)

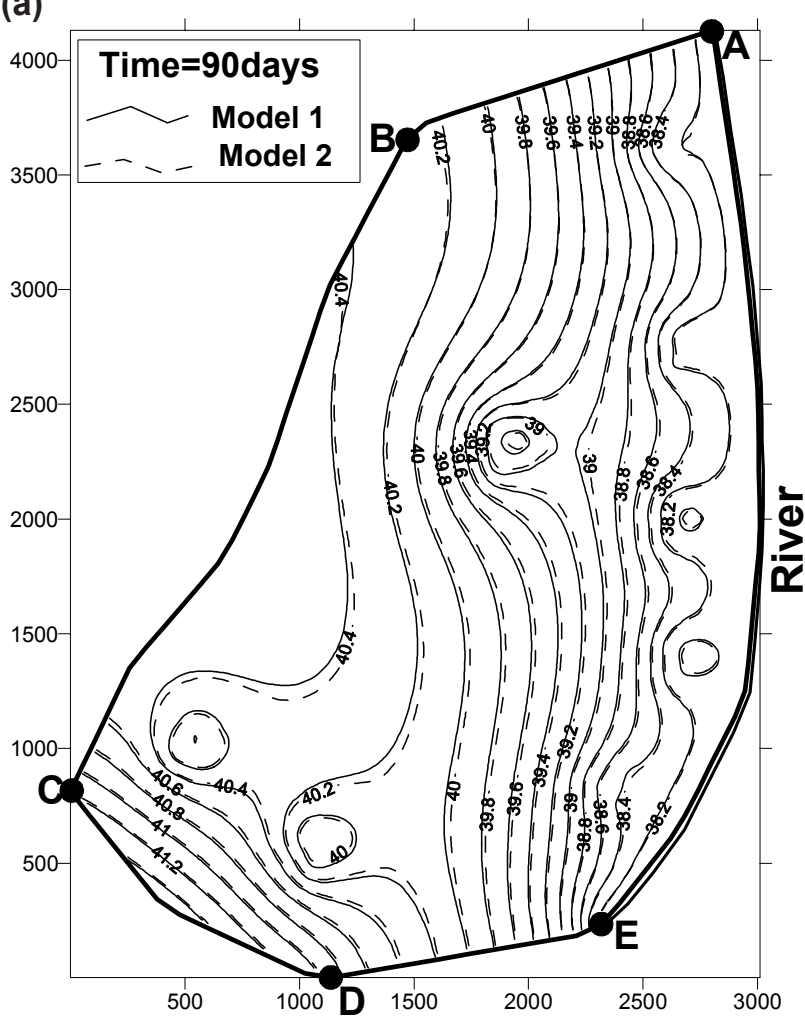

nodes. The lengths of the sides of the elements range between 100 $\mathrm{m}$ and $140 \mathrm{~m}$, while numbering of the nodes was done in an optimal fashion such that the bandwidth of the coefficient matrix is 69 . Adopting a time step of $5 \mathrm{~d}$ in the current model, the contours of water table levels are presented in Figs. 10a, 10b and 10c at times of $90 \mathrm{~d}, 180 \mathrm{~d}$ and $360 \mathrm{~d}$, along with the results of model 1 which used a uniform time step of $2 \mathrm{~d}$. The hydrographs at sections $\mathrm{P}_{1}, \mathrm{P}_{2}$, $\mathrm{P}_{3}$, and $\mathrm{P}_{4}$ along the river, as indicated in Fig. 9, are presented in Fig. 11. While there is generally good agreement between the solutions from the two Green element models, we observe, as expected, the expanding zone of influence of the wells with time, with no noticeable influence zone for the well at $Q_{5}$ which has the least strength. In addition, the influence of the influx from the boundary $\mathrm{CD}$ is felt by the wells $\mathrm{Q}_{6}$ and $\mathrm{Q}_{7}$ which are recharged largely by the influx from this boundary, as indicated by the higher water table gradients on the south-western side of these wells. The decrease in discharge hydrographs from section $\mathrm{P}_{1}$ to $\mathrm{P}_{4}$ is largely due to the effects of the wells $\mathrm{Q}_{1}, \mathrm{Q}_{2}, \mathrm{Q}_{3}$, and $\mathrm{Q}_{4}$. (b)

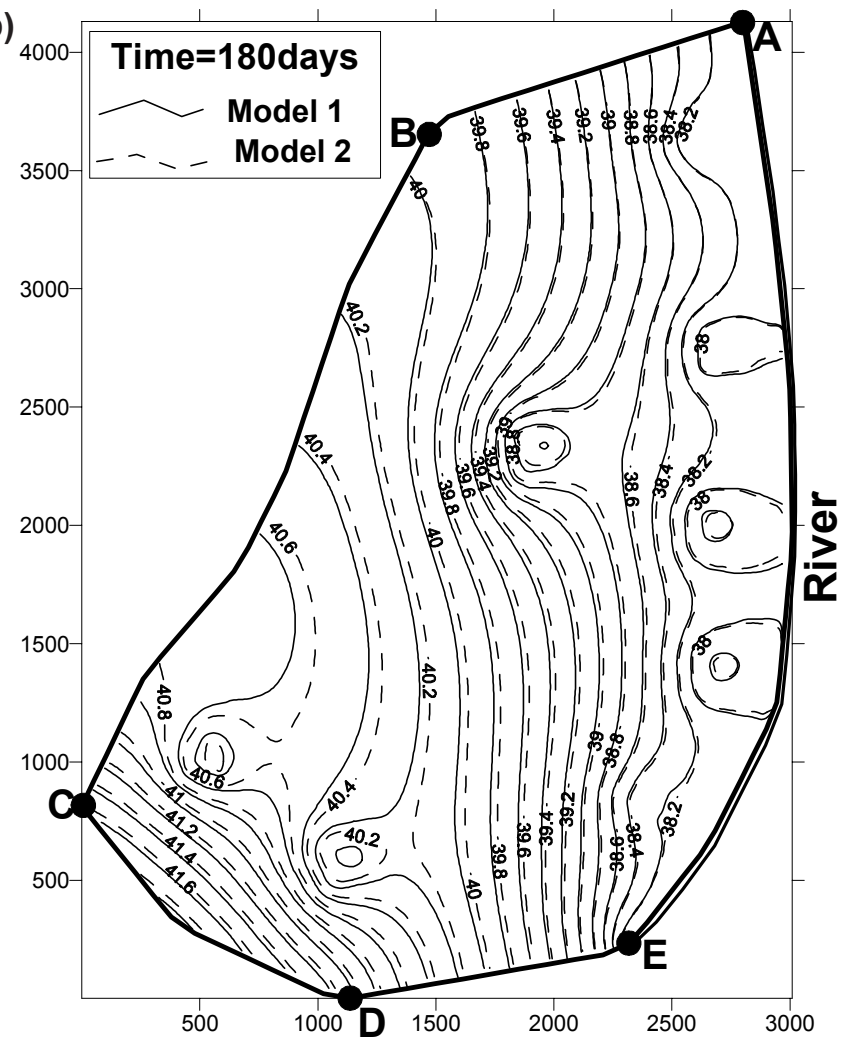

(c)

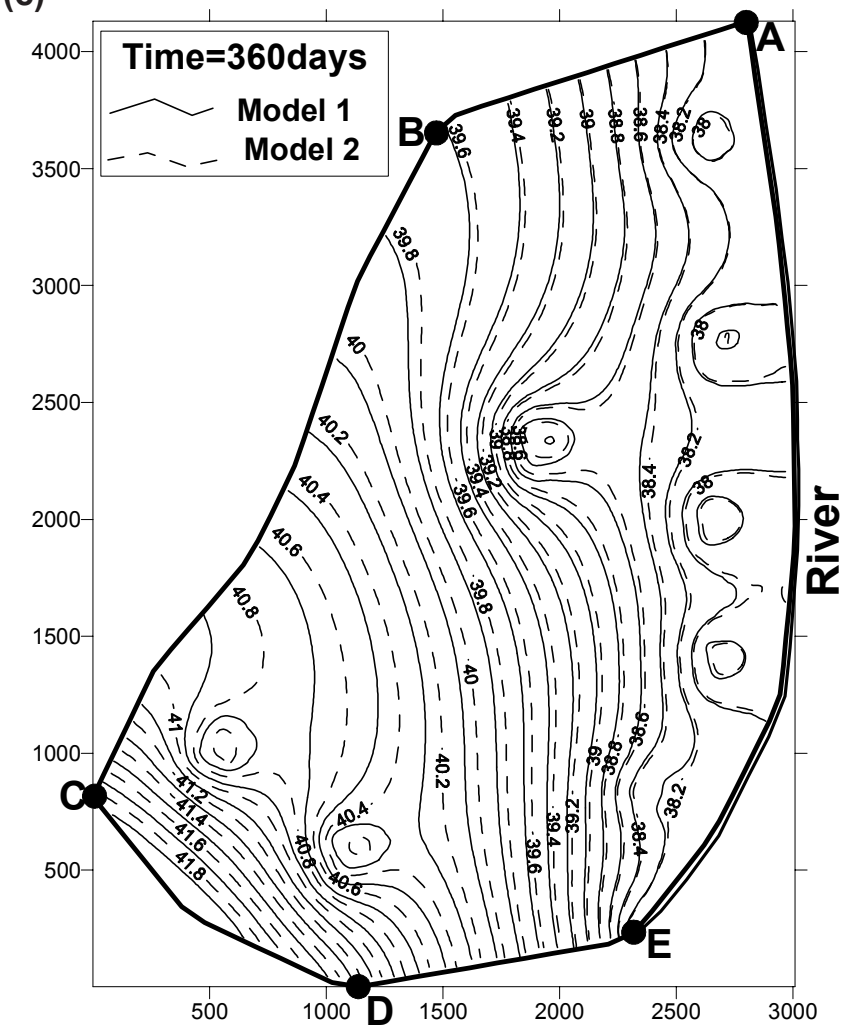

Figure 10

Contours of water table elevations for example 4 (a) time $=90 \mathrm{~d}$, (b) time=180 d, and (c) time $=360 \mathrm{~d}$ 


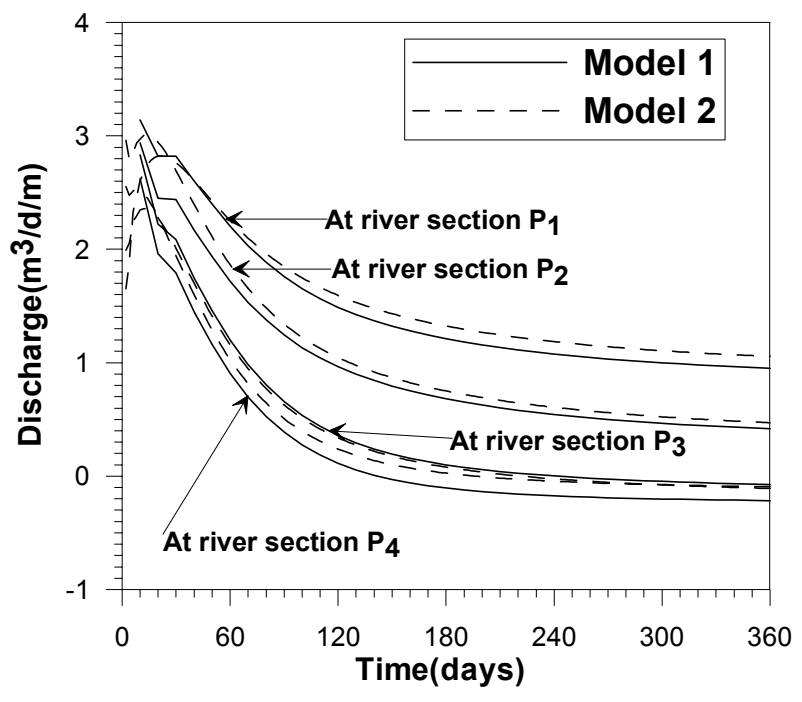

Figure 11

Green element solution of example 4 for discharge hydrograph at different sections of the river

\section{Conclusion}

This paper has presented another robust Green element formulation for the stream-unconfined flow problem. It is based on the transient Green's function of the diffusion differential operator, and it is capable of simulating regional groundwater flows in heterogeneous, unconfined aquifers of variable bedrock elevation, with point and distributed stresses of arbitrary variation. Its computational complexities, which involve handling such functions as the Exponential Integral and Error function, in contrast to the simplicity of the Green element model with Logarithmic fundamental solution, seem to be compensated for by the larger time step that can be adopted to achieve comparable accuracy. The appeal of this numerical feature, notwithstanding, this current model provides another viable formulation for solving streamunconfined aquifer flows along the lines of the Green element methodology.

\section{Acknowledgements}

The financial support received from the Swedish International Development Cooperation Agency (SIDA) for this water-related research project, that assisted the author in carrying out this work at the National University of Science \& Technology (NUST) is acknowledged.

\section{References}

BEAR J (1979) Hydraulics of Groundwater. McGraw-Hill, New York. $120-123$.

BOUSSINESQ J (1904) Recherches Theoretiques sur l'ecolement des Nappes d'eau infiltrees dans sol et sur le debit des sources. J. de Mathematiques Pures et Appliquees 10 5-78 363-394.

BUTTERWORTH JA, MACDONALD DMJ, BROMLEY J, SIMMONDS LP, LOVELL CJ and MUGABE F (1999) Hydrological processes and water resources management in a dryland environment III: Groundwater recharge and recession in a shallow weathered aquifer. Hydrol. \& Earth Syst. Sci. 3 (3) 345-352.

CABRERA G and MARINO MA (1976) Dynamic response of aquifer systems to localized Recharge. Water Resour. Bull. 12 (1) 49-63.

DESAI CS (1973) Approximate solution for unconfined seepage. J. Irrig. Drain. Div., ASCE 99 71-87.

DILLON PJ and LIGGETT JA (1983) An ephemeral stream-aquifer interaction model. Water Resour. Res. 19 (3) 621-626.

HORNBERGER GM, EBERT J and REMSON I (1970) Numerical solution of the Boussinesq equation for aquifer-stream interaction. Water Resour. Res. 6 (2) 601-608.

IBRAHIM HA and BRUTSAERT W (1965) Inflow hydrographs from large unconfined aquifers. J. Irrig. Drain. Div., ASCE 94 21-38.

LOCKINGTON (1997) Response of unconfined aquifer to sudden change in boundary head. J. Irrig. Drain. ASCE 123 24-27.

ONYEJEKWE OO, KARAMA AB and KUWORNOO DK (1999) A modified boundary integral solution of recharging and dewatering of an unconfined homogeneous aquifer. Water SA 25 (1) 9-14.

ROCHESTER EW and KRIZ GJ (1968) Model study of the boundary effects on ditch drainage. J. Irrig. Drain. Div., ASCE 94 403-504.

TAIGBENU AE (1995) The Green element method. Int. J. Num. Meth. Eng. 38 2241-2263.

TAIGBENU AE (1999) The Green Element Method. Kluwer Acad. Publishers, Boston, 376 pp.

TAIGBENU AE (2001a) Unsaturated-flow simulation with Green Element Models. J. of Hydraul. Eng. ASCE 127 307-312.

TAIGBENU AE (2001b) Simulations of unsaturated flow in multiply zoned media by Green element models. Transport in Porous Media 45 387-406.

TAIGBENU AE (2003) Features of a time-dependent fundamental solution in the Green Element Method. Applied Math. Modelling 27 (2) $125-143$.

TAIGBENU AE (1999) Three Green element models for the diffusionadvection equation and their stability characteristics. Eng. Anal. with Bound. Elem. 23 577-589.

TAIGBENU AE and LIGGETT JA (1986) An integral formulation applied to the diffusion and Boussinesq equations. Int. J. Numer. Meth. Eng. 23 1057-1079.

TAIGBENU AE and ONYEJEKWE OO (1999) Green's function-based integral approaches to nonlinear transient boundary-value problems (II). Appl. Math. Modell. 23 241-253. 
